\title{
Literature Review for Integration of Urban and Rural Social Endowment Insurance Development
}

\author{
Juan Luo ${ }^{1}$ \\ ${ }^{1}$ Shanghai Jiao Tong University, China \\ Correspondence: Juan Luo, Antai College of Economics and Management, Shanghai Jiao Tong University, Shanghai, \\ 200052, China
}

Received: January 2, 2015 Accepted: January 10, $2015 \quad$ Online Published: January 10, 2015

doi:10.5430/sass.v2n1p30 URL: http://dx.doi.org/10.5430/sass.v2n1p30

Project supported by the Shanghai philosophy and social science planning Youth Research (2013EJB003) and Shanghai Municipal Education Commission and Shanghai Municipal Education Development Fund "dawn plan" (10GG22)

\begin{abstract}
The establishment of an endowment insurance system which is fairness and for all urban and rural residents has been the development direction and goal of the social security system in China. Different scholars research the development for integration of urban and rural endowment insurance system from different angle of views, theories and methods. This paper sum up the research achievements inland, carding and review of the existing literature from the connotation, key problems, realizing path and other aspects of the integration of urban and rural endowment insurance.
\end{abstract}

Keywords: endowment insurance; integration of urban and rural; literature review

After the Third Plenary Session of the introduction of eighteen, Ministry of human resources and social security of "Provisional Measures the Combination of Urban and Rural Endowment Insurance System", defined the development trend of "combination of three insurances". On December 23, 2014, vice premier of the State Council on behalf of the State Council Ma Kai made a work report to the twelfth session of the Twelfth National People's Congress on promote the development for integration of urban and rural social security system construction, which indicates that China has entered a new stage of social security cause by the urban to integration development of urban and rural. Around the theme of integration of endowment insurance of urban and rural, the scholars of our country have discussed, but there still exist some differences in some key questions, which produced great distress in the actual operation level, hindering the smooth implementation for the integration of urban and rural social endowment insurance.

\section{Connotation for Integration of Urban and Rural Social Endowment Insurance}

Wang Xiaodong (2012) considers integration of endowment insurance of urban and rural, refers to during the design and operation of the endowment insurance system in urban and rural areas, a breakthrough of "fragmentation" system pattern under two-spot structure, starting from the principle of the integration of the overall development of urban and rural areas, construction of the system of endowment insurance system covering urban and rural residents of the unity of all, in order to achieve the indifference protection for endowment insurance rights of the urban and rural residents. Li Xiaolin (2014) thinks of integration of endowment insurance of urban and rural is consider the urban and rural as a whole, gradually make the urban and rural workers social endowment insurance system and residents social endowment insurance system for the merger of the system of social endowment insurance which is "unified management, unified standards, freedom of choice", finally make urban and rural residents can get equal endowment insurance.

Six plenary sessions put forward, to 2020 to achieve the target of "preliminary establishment of a social security 
system covers urban and rural residents". Li Yingsheng (2006) thinks, the goal is not only refer to make urban and rural residents are able to enjoy social security at that time, but to through the scientific design to achieve the linking of implementation of the basic social security items and standards of treatment in urban and rural areas, achieve the integration of urban and rural areas, and the latter is more important than the former. He Ping (2005) thinks, the long-term goal of integration of endowment insurance system of urban and rural is "equality of urban and rural residents enjoy social security". However, to achieve this goal is still a long process, need to gradually push and step by step.

Overall, for the integration of endowment insurance of urban and rural, scholars from different angle of view analysis although their meanings, but basically agree with the overall planning of urban and rural endowment insurance is to establish a endowment insurance system which is fair and everyone could enjoy.

\section{Focus Problems for Integration of Endowment Insurance of Urban and Rural}

In view of the problems of endowment insurance appears in integration of urban and rural areas, the attention of academic circles is more, overall, is mainly reflected in the following aspects:

(1) The problem of mode for integration of endowment insurance of urban and rural

As the institutional reasons, China's endowment insurance system since birth there is division of urban and rural system, the treatment difference is obvious. Since 1997 our country reform from pay as you go system to partially funded system, Zheng Bingwen (2003) adhere to the "represents the nominal account system", he has been consider that the nominal account system is the rational choice of China`s endowment security system, but also stressed that it only as a transitional system arrangement, and will eventually lead to accumulation system. His view is also supported in Zheng Wei's (2010) research, but Zheng Wei is more emphasis on the public governance risk brought by the nominal account system. Long Zhaoyang, Shen Shuguang (2011) considers transition bring crowding out effect, market distortion and reverse redistribution of income and many other negative effects to the economy, should be establish the basic endowment insurance system of combining with non contributory endowment plans and national basis payment type nominal account system scheme. Zeng Jin (2010) suggests that carry out "social pooling nominal account system" plus "personal accounts full funding system". Social overall nominal account system to implement the notional defined contribution PAYG, form individual basic account (social pooling account), as account (Finance), individual account is gradually small solid. While some scholars advocate the direct personal accounts, to protect of personal endowment rights of accumulation, in order to cope with the aging of the population (Yang Yansui, 2010). Individual accounts truly realize "combination of social pooling and individual account, account management, real account operation" (Liu Changping, 2011), is the key to successful transition of endowment insurance in China (Peng Haoran, 2009). Zheng Gongcheng (2011) suggests that under the premise of our country endowment insurance to the rapid advance of universal, should change the social security system construction oriented which value of social insurance and social assistance, despise of social welfare, value of employment group, despise of widespread people, complete the short board of social welfare construction lag, build a real sound social security system.

\section{(2) The problem of different population for integration of endowment insurance of urban and rural}

Most scholars believe that integration of urban and rural areas is not absolutely uniform, but uniform of different layers and differences. On this view, scholars claim endowment security of urban and rural development should adhere to the principle of multi level, should be build the system aimed at different groups respectively, realize the wide coverage of system, and then fusion gradually, realized the unified system. Academic circles concentrate on how to design the transition model of urban and rural endowment system, have widely discusses on the construction of endowment security system for groups of rural residents, landless farmers and migrant workers.

In view of the endowment insurance system for rural residents, the construction of rural resident endowment insurance system is the key and difficult problem of development for integration of endowment insurance of urban and rural. Although China has established an endowment insurance system in rural areas, but the treatment of rural residents and city residents have a certain gap. The academic circles on how to establish and improve the endowment security system of rural residents carry out a lot of researches, to sum up, there basically have the following kinds of ideas: the first approach is to take the personal account. Su Shengqiang (2009) argues that the rural endowment security should continue to pursue a personal account, completely accumulation system by using the flexible payment, all the funds into personal accounts, can with the flow of farmers surrender or reinsurance. The second approach is to take the individual accounts mode plus zero pillar. Liu Changping (2008), Hua Yingfang (2008) come 
up with that rural endowment security system should take the minimum endowment claims plus rural endowment insurance individual account model, in which the minimum endowment constitute the zero pillar, by the financial subsidies, the standard uniform. The third idea advocated by the general tax as a source of funds for GSP welfare model.

According to the landless farmers of endowment security system, the academic circles from the aspects of theory and practice on how to build and perfect the endowment insurance system of land expropriated farmers has carried out many researches, to sum up, there basically have the following kinds of ideas: a view of commercial insurance to give full play to the insurance function of social management, is the efficient way to solve the rural endowment endowment problem for whose land was expropriated. Xin Xiaobai (2005) put forward the landless farmers endowment insurance by government security and commercial insurance combined model. Another view is firmly opposed to landless farmer endowment insurance with commercial insurance model. Zhang Hairong (2005) thinks that commercial insurance not only make it difficult for land expropriated farmers to enjoy the fruits of social development, and the profit driven nature of commercial insurance can only cover a limited high-income groups, not to be universal coverage of landless farmers.

The endowment insurance system for migrant workers, how to design the system of endowment insurance of migrant workers, the academic circles mainly have the following several points: the first point of view is that the endowment insurance system for migrant workers choose should fully consider its segmentation, according to the choice for the corresponding security system of migrant workers groups of different employment status. Zheng Gongcheng (2002) thinks it necessary to have a stable career design more than two programs for workers and no stable job of migrant workers to choose, and as a national policy. The second view is that the establishment of a separate endowment system for migrant workers, Zhang Ruikai (2011) put forward the payment and treatment level of basic urban workers and unity, coordination of system operation is far higher than the farmers "independent - cohesion" type of migrant workers social security model, provides a breakthrough on the system in order to realize the integration of urban and rural social security. The third view is that to build another endowment insurance system for migrant workers while is beneficial to improve the migrant workers participation rate, but there will be no end of trouble in the future. All migrant workers should be treated equally, and carrying out the same system as workers, or to reduce the rate of payment or payment base, which will be directly incorporated into the job security of migrant workers. The fourth view is that migrant workers will be included in the rural social endowment insurance. Yang Lixiong (2004) believes that the migrant workers into the urban social security system or refer to the establishment of an independent social security of migrant workers are not feasible in theory and practice, only when the migrant workers into the rural social security system can fundamentally solve the problem of migrant workers social security.

(3) Problems for transfer of the endowment insurance

Portability of endowment in China is mainly run by the government endowment insurance relationship can't be transferred. The academic circles on how to build a cohesive transfer mechanism, and gradually realize the transition from the division of urban and rural endowment security to the integration of urban and rural areas, has been widely discussed, research results at present there are two kinds of policy orientation: one is based to the existing policy, research for be specific measures for the overall regional endowment insurance through; another kind is to emphasize design to the endowment insurance system for portable service, starting from the endowment insurance system innovation, research on the construction of portable endowment insurance system.

(1) Policy research of transfer between worker endowment insurance co-ordinate regional

The endowment insurance of our country is still at the provincial level case, the insured person move from one area to another overall planning area, design of only transfer system individual account and not transfer co-ordinate fund make it not admit that capture expends fixed number of year in other pooling area, often suffer from the lowest capture expends fixed number of year loss. Between the claims in the current worker insurance are established on the basis of overall regional transfer channel, scholars agree that co-ordinate regional payment should recognize and incorporate computation, but problem of insured person in each payment rights how to confirm and inflow and the inflow how to balance interests and so on, there is no consensus.

(2) Transfer and connection of the urban and rural endowment insurance relationship

Worker and rural social endowment insurance personal accounts are set up, the insured person flow, worker and rural endowment insurance individual account will post merger or insurance personal accounts in accordance with the conversion of accumulated amount of payment standards for rural payment period. The social pool of worker social endowment insurance, the new agricultural insurance has no arranged corresponding system. Yin Qingshuang and 
Yang Yingqiang (2007), Zhang Weibing (2009) believe that it should be transfer the social pooling account all the amount to the personal account of rural social endowment insurance. Rural social endowment insurance fund is mainly based on the individual account, endowment insurance relationship transfer and connection is simple. From the countryside to the city endowment insurance relationship transfer connection can through combined personal account of worker and rural social endowment insurance, also can be achieved by using for personal accounts in accordance with the conversion of accumulated amount of payment standard of worker insurance capture expends fixed number of year for certain, and according to the standard of worker endowment sends annuities. Liu Changping, Yin Baoming (2010) put forward the new agricultural and worker based endowments take transfer scheme that "as payment plus substitution rate standard to determine treatment plus accumulation endowment rights".

(3) The reform of the existing endowment insurance system

Some scholars think that it should be from the reform of endowment insurance system to solve problems of China's endowment insurance system transfer. Zeng Jin (2010) suggests in maintaining social pooling cash based on the pay as you go system, post nominal account into the basic pension insurance, make nominal account real account when the insured transfer, along with all away, the last insured area to be responsible for their pensions.

\section{Study on Development Path of Integration of Endowment Insurance of Urban and Rural}

Scholars advocate of balancing urban and rural development agree that the ultimate goal of balancing urban and rural development is to achieve the integration of urban and rural endowment security, but there are differences on the development strategy of the integration of urban and rural endowment security.

(1) A step development path

A step development path is advocated in one step to establish a unified basic endowment security system. Zhang Yinghong (2002) considers that the establishment of a unified social security system is to protect the citizens' basic rights under the constitution, China has fully achieved the level which many developed countries began to set up their unified social security system. Therefore, our country should regard the endowment security as a basic security program, all citizens have no identity of the points in the same system.

On the design of account structure, Lu Haiyuan (2009) presents a unified endowment insurance system to take the basic pension and individual accounts combined mode, the basic pension of national unity, have no identity, regional differences, individual account pension reflect differences in pension levels of identity and area. Niu Guimin (2010) considers not only the individual account annuities will have differences, but also the national basic pension should also reflect differences in regional economic development level, different areas of national basic pension benefits cannot be the same.

Hu Ping, Wang Chong (2009) believe that the endowment insurance system according to the actual situation of different regions and different groups, to establish social security accounts for the national of "households with people go", social security accounts are divided into an account can be immediately extracted and an account must meet certain capture expends fixed number of year can extract. Feng Shangchun, Ding Xiaochun (2009) put forward the "family account" as the basis, all family members share an account, covering pension, medical, education and other content, as the basis of social guarantee system in urban and rural areas.

(2) Multi step development path

A part of scholars believe that the objective can not only to realize the unity of urban and rural in place, but should take the development path of advancing step by step and progressive unity.

Xue Xingli (2006) and Yuan Yandong (2007) put forward the strategy of the development of urban and rural endowment security of the "two steps". Among them, Xue Xingli proposed the first stage of balancing urban and rural development (2006-2015) to realize the urban and rural social security system change from the "unified planning, system is different" to "unified part of the system, different standards"; the second stage (2015 - 2025) is the realization of social guarantee system in urban and rural areas change from the "unified fusion " to the " basic unification". Yuan Yandong puts forward "two step" development strategy is from the "transition plan" to "target plan". "Transition plan" is same to "target plan" system mode, both making the coverage of worker insurance which current social pooling and individual account combining to all the people.

Chen Dongqi (2002) and Mi Hong (2008) propose endowment security of urban and rural development should take the "three step" development strategy. Among them, Chen Dongqi from the imbalance between urban and rural areas of the national conditions, considers the first step is to put forward a unified social security system of the city; the 
second step is let the city social security items extended to rural areas, to achieve initial unification of urban and rural social security; the third step is the unity of the full realization of the urban and rural social security. Mi Hong (2008) from the point of economic development level of China's regional imbalance situation, put forward the first step (as of 2020) is to establish the social security system covered of urban and rural residents; the second step (from 2021 to 2035) achieve a dynamic connection of "big area" urban and rural endowment insurance which regional division of East, Middle, West; the third step is to achieve the urban and rural endowment security from a big regional cohesion to cohesive nationwide in 2049.

Liu Lingling (2008) and Zhang Junliang (2010) put forward the strategy of coordinated development of urban and rural social security by taking the gradient development. Among them, Liu Lingling on the basis of balancing urban and rural development level, divide the gradient development strategy into "unified", "middle stage", "integration of urban and rural" and "urban and rural integration" four development stages.

Zheng Gongcheng (2008) realized that our country endowment security system construction goal needs three steps: the first step (2008-2012): the establishment of multiple pension security system orderly combination, to achieve full coverage on the system level. The second step (2013-2020): pay endowment insurance as the main body of the endowment security system, the realization of all stable overall shaping, fairer pension and related services. The third step (2021-2049): promote the system integration, the realization of all enjoy a decent life.

\section{Research Review}

Research on the endowment insurance of urban and rural areas throughout the academic, policy documents issued and government departments, it can be seen, the planning of urban and rural endowment insurance of our country be imperative, brook no delay. In this study, discovery after combing the relevant research literature, research in this field still needs further study in place:

(1) The existing study involves the problem of endowment insurance of balancing urban and rural development has not got rid of the restriction of identity. Only some scholars advocate unification in the design of the system completely eliminates the household register identity discrimination, other scholars in the design of endowment security system is still branded identity division traces.

(2) The existing research in view of safeguarding system covering the object, research level, etc. also need further study. In the aspect of integration in the coverage of urban endowment insurance, be equivalent to town worker endowment insurance, ignoring the no fixed work, non formal employment pension demand of household registration population in cities. In terms of the integration of security level, the new type of rural social endowment insurance and urban social endowment insurance has not been fully studied in alternative integration rate. In the research visual angle range, the existing research in landless farmers, migrant workers and other groups of pension demand, more from the "ought" to carry out research perspective, while the perspective of feasibility especially economic feasibility to carry out research is less.

(3) The existing research advice to the development for integration of endowment insurance for urban and rural often from the framework of the existing system, lack of the existing system of inheritance. Features: on the one hand preference from the original endowment security system framework according to the characteristics of different groups, set up a separate kitchen be arranged to establish independent social security project; on the other hand tend to overhaul of the existing system in order to solve endowment security system reform in the process of development problems, such as some scholars claim make the formation of nearly 30 years of reform China's urban workers pension insurance personal account combined system model and thoroughly reform to solve the endowment insurance transfer problems.

(4) Transfer of pension relationship continued research is still weak. In the research content, there are more policy research between the urban workers pension insurance co-ordinate regional transfer, endowment insurance relationship between urban and rural areas is still continuing on in the study of the transfer and continuation of the necessity, principle and other macro level, study of specific way of transferring and connection is less, and the institutions of the pension system and urban worker pension insurance transfer and continuation of study are been ignored.

\section{References}

He Junmin, \& Yang Bin. (2013). Research on Differences of Chinese Urban and Rural Endowment Insurance System 
-- Based on the Perspective of Integration of Urban and Rural. Journal of Zhengzhou University (Philosophy And Social Sciences Edition), 2013(06), 85-89.

Li Yougen, \& Zhu Xiaoling. (2010). Designing the Peasant Worker's Pension Insurance Model under the Background of Planning the Urban and Rural as a Whole. Ecological Economy, 2010(10), 70-74.

Liu Changping. Exploration of the Way to Balance the Social Old-age Insurance System for Urban and Rural Residents. Social Security Studies, 2009(02), 14-17.

Tong Guang Yin, \& Xue Xingli. (2009). The Implementation Path and Strategy Layout of Integration of Urban and Rural Endowment of Urban and Rural. Special Zone Economy, 2009(01), 220-222.

Wang Xiaodong. (2014). Discussion on the Overall Level of Urban and Rural Social Endowment Insurance System from the Perspective of Further. Dongyue Tribune, 2014(02), 127-131.

Yang Bin, \& Ding Jianding. (2014). From the Division to Unity of Urban and Rural Development: China's Pension Insurance System Structure Development Research. Social Security Studies, 2014(01), 20-26. 